\title{
OXYGEN COST AND ENERGY EXPENDITURE OF RUNNING IN TRAINED RUNNERS
}

\author{
J. L. MAYHEW, Ph.D. \\ Department of Physical Education, University of Illinois, Champaign, IIlinois, USA
}

\section{ABSTRACT}

The oxygen cost and energy expenditure of submaximal treadmill running was evaluated in 9 male distance runner The oxygen consumption - running speed relationship was highly significant $(r=.917)$ and linear over the entive aerobic range. The caloric cost of $0.97 \mathrm{Kcal} / \mathrm{kg} / \mathrm{km}$ was in close agreement with values found in the literature and was independent of running speed. The caloric cost per unit distance and time increased with acceleration in running spee忽 The slope of the regression line of oxygen consumption on running speed appear to measure a different component of efficiency than the fractional utilization coefficient of aerobic capacity. There is apparently a wide variation in the oxygen cost of running in trained runners.

\section{INTRODUCTION}

It is generally accepted that the relationship between running speed and oxygen consumption is linear throughout the entire aerobic running range (8-24 $\mathrm{km} / \mathrm{hr}$ ). Most of the studies investigating this problem have used the motor-driven treadmill to maintain a constant running speed. When oxygen consumption has been determined during track running, however, the relationship is slightly curvilinear but may be represented by linear regression (Pugh, 1970). The slope of the regression line of oxygen consumption on running speed may offer one means of assessing the efficiency of running among different subjects (Foster, 1972).

There appears to be considerable variation in oxygen consumption at submaximal running speeds between trained and untrained runners (Dill, Talbott et al., 1930; Foster, 1972; Seller, 1973; Costill, Thomason et al., 1973). Improvement in running efficiency resulting from training has been shown to be $\mathbf{0 . 8 \%}$ (Margaria, Cerretelli et al., 1963; Wyndham, Strydom et al., 1971; Mayhew and Andrew, 1975), although some research (Dill, Talbott et al., 1930; Dill, 1965) has indicated that it can

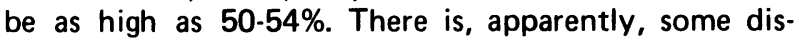
crepancy concerning the effect of training on the efficiency of running in trained subjects. Furthermore, the variability of oxygen cost during running in trained subjects is in question.

Therefore, the purpose of this study was to determine the oxygen consumption of horizontal treadmill running in trained adult men. Factors that might contribute to differences in running efficiency were analyzed. Com-

Present address: Human Performance Laboratory, Physical Education Division, Northeast Missouri State University, Kirksville, Missouri 63501, USA. parisons with other studies in the literature were made to determine the variability in oxygen cost of running.

\section{METHOD}

The subjects for this study were 9 volunteers who had been training for 3-13 years. While these runners trained by running 24-128 km/wk, their performance abilieies were quite varied. Physical characteristics of the subjęts are shown in Table I.

\begin{tabular}{|c|c|c|c|c|}
\hline Subject & $\begin{array}{l}\text { Age } \\
\text { (yrs) }\end{array}$ & $\begin{array}{l}\text { Height } \\
\text { (cm) }\end{array}$ & $\begin{array}{l}\text { Weight } \\
\text { (kg) }\end{array}$ & $\begin{array}{l}\dot{\mathrm{VO}}_{2} \max \\
(\mathrm{ml} / \mathrm{kg} / \mathrm{min}\end{array}$ \\
\hline JA & 23.75 & 179.0 & 78.60 & 64.1 \\
\hline RB & 22.50 & 170.0 & 64.15 & 72.5 \\
\hline GG & 21.75 & 171.0 & 60.50 & 67.2 \\
\hline BH & 26.00 & 183.2 & 74.60 & 75.7 \\
\hline JM & 30.16 & 179.3 & 79.30 & 60.7 \\
\hline DM & 25.92 & 176.5 & 68.95 & 72.4 \\
\hline JO & 30.75 & 186.5 & 70.55 & 64.2 \\
\hline RP & 20.83 & 165.7 & 55.60 & 69.5 \\
\hline BW & 31.58 & 171.5 & 54.90 & 60.7 \\
\hline Mean & 25.92 & 175.9 & 67.46 & 67.4 \\
\hline SD & 4.08 & 6.8 & 9.25 & 5.4 \\
\hline
\end{tabular}

All of the subjects were familiarized with treadmilp running prior to testing. Each subject was evaluated if the laboratory on from 1 to 5 separate occasions over $\stackrel{0}{0}$ 14-day period. Submaximal running speeds between $13 \frac{8}{4}$ and $295 \mathrm{~m} / \mathrm{min}(5-11 \mathrm{mi} / \mathrm{hr})$, in $6.7 \mathrm{~m} / \mathrm{min}(0.25 \mathrm{mi} / \mathrm{h}$ 至 increments, were assigned randomly to each subject. Four subjects ran at 12 different speeds, 2 subjects ran at 11 speeds, 1 subject ran at 8 speeds, and 2 subject ran at $\mathbf{4}$ speeds for a total of $\mathbf{8 6}$ observations. 
Each subject reported to the laboratory at least 2 hours postabsorptive. After body weight was recorded (running shorts only), the subject performed a 5-minute warmup at $147 \mathrm{~m} / \mathrm{min}$. Following a 5-minute rest, the subject performed 3 or 46 -minute submaximal runs, each separated by at least 15 minutes rest.

Oxygen consumption was determined by open circuit spirometry. Pulmonary ventilation, expired gas temperature, and breathing frequency were recorded using a Parkinson-Cowan (CD4) dry gas meter with an ink recorder. One-minute aliquots of expired gas were collected during the 5th and 6th minutes of each run, the mean used to calculate oxygen consumption at a given speed. The samples were analyzed within 5 minutes after collection on electronic analyzers (Beckman E-2 $\mathrm{O}_{2}$ and MSA Lira $300 \mathrm{CO}_{2}$ analyzers) that were routinely calibrated throughout the testing using reference gases previously analyzed on a Lloyd-Gallenkamp chemical apparatus. Heart rate was recorded during the last 15 seconds of the 5th and 6th minutes by telemetered electrocardiography, the mean representing the heart rate at a given speed.

After all submaximal runs had been completed, each subject performed a grade-incremented maximal oxygen $\frac{0}{7}$ intake test (Costill, Thomason et al., 1973). Depending 3 on the runner's ability, a treadmill speed between $?$ $215-268 \mathrm{~m} / \mathrm{min}$ was chosen. The grade was increased $2.5 \%$ every 2 minutes until voluntary termination by the $\stackrel{9}{+}$ subject. One subject performed his maximal oxygen intake test 30 minutes after completing 4 submaximal runs, while all others performed the $\mathrm{VO}_{2} \max$ test on a separate day.

\section{RESULTS}

The oxygen consumption - speed relationship in this study was observed to be linear over the entire range of $\frac{O}{6}$. running speeds (Figure 1). The correlations between 3 oxygen consumption and speed were high for each in- $\vec{\exists}$ dividual (Table II) and indicate that a linear regression $\omega$ may be applied to each runner. The overall correlation ( $r \vec{A}$ $=.917$ ) was slightly lower and the standard error of $\sigma$ estimate (SEE $=3.5 \mathrm{ml} / \mathrm{kg} / \mathrm{min}$ ) slightly greater than 5 those for each individual, although the regression re- $\vec{C}$ mained linear. The prediction equation for 86 observa- $\mathbb{D}$ tions was: $\mathrm{VO}_{2}(\mathrm{ml} / \mathrm{kg} / \mathrm{min})=0.1991$ Speed $(\mathrm{m} / \mathrm{min})-\frac{\vec{T}}{\Phi}$ 0.82 .

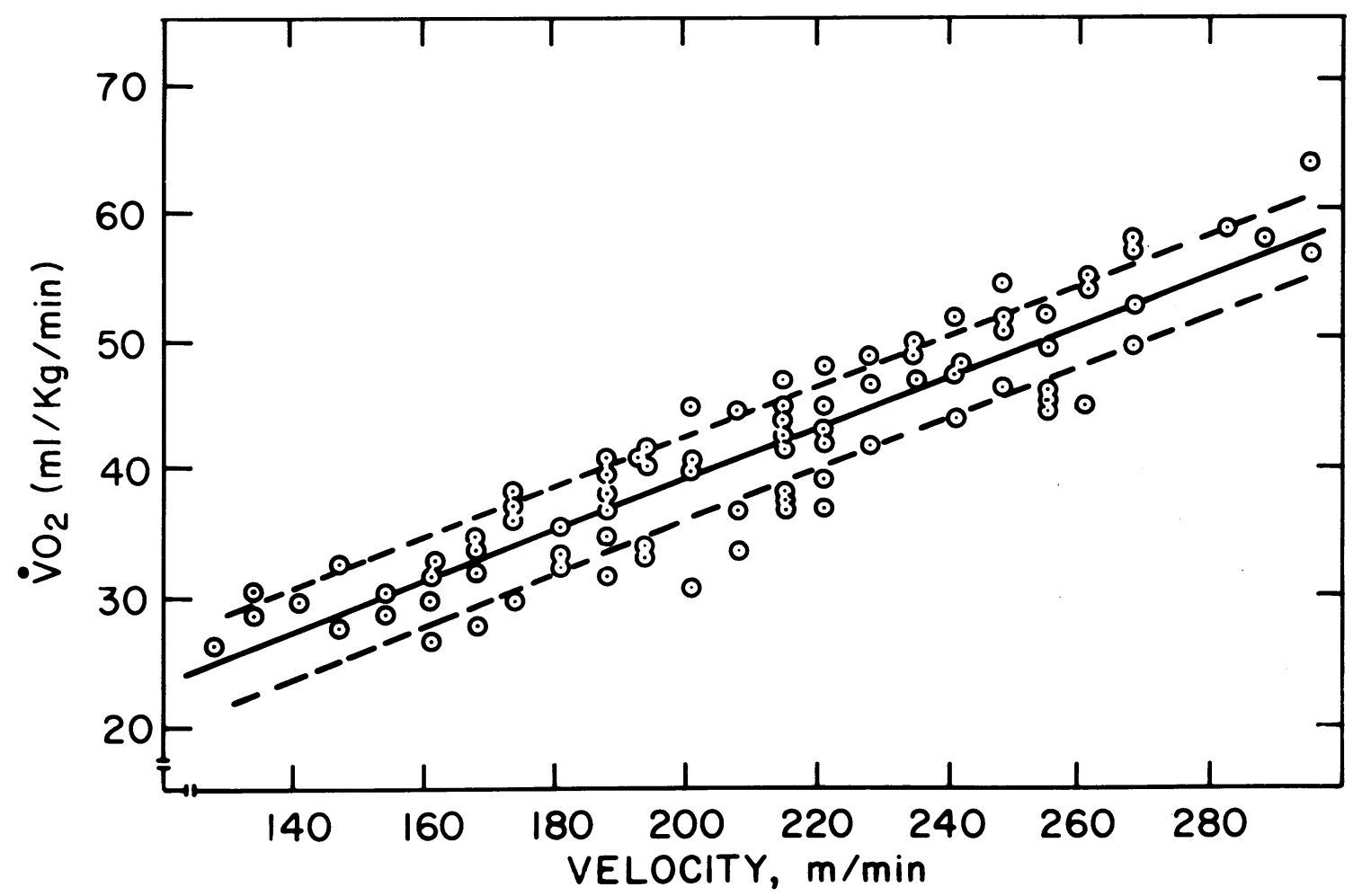

Figure 1. Relationship between running speed $(\mathrm{m} / \mathrm{min})$ and oxygen consumption $(\mathrm{m} / \mathrm{kg} / \mathrm{min})$ in 9 trained runners. $V \mathrm{O}_{2} \mathrm{O}^{2}$ $(\mathrm{ml} / \mathrm{kg} / \mathrm{min})=0.1991$ Speed $(\mathrm{m} / \mathrm{min})-0.82(r=.917$, SEE $=3.5 \mathrm{ml} / \mathrm{kg} / \mathrm{min})$. 
TABLE II

Energy Expenditure during Treadmill Running in Trained Men $(n=9)$

$\begin{array}{llll}\text { Subject } & \mathbf{r} & \begin{array}{l}\text { Regression } \\ \text { Slope }\end{array} & \text { Intercept } \\ \text { JA } & .982 & .2025 & +1.14 \\ \text { RB } & .987 & .2131 & -2.60 \\ \text { GG } & .995 & .2157 & -0.13 \\ \text { BH } & .980 & .2189 & -9.14 \\ \text { JM } & .959 & .1600 & +4.50 \\ \text { DM } & .990 & .2151 & -4.09 \\ \text { JO } & .964 & .1805 & -1.29 \\ \text { RP } & .999 & .2054 & -0.65 \\ \text { BW } & .980 & .2058 & -0.37 \\ \text { Mean } \pm \text { SD } & .917^{\mathrm{a}} & .1991^{\mathrm{a}} & -0.82^{\mathrm{a}} \\ \text { SEC } & .354 & .0092 & \end{array}$

a Overall regression equation calculated from 86 observations.

$b_{\text {Mean }} \pm$ SD of the average value for each runner.

c Standard error of the mean (SD $/ \sqrt{n})$.

The caloric cost of running is shown in Table II. The caloric cost per unit distance $(\mathrm{Kcal} / \mathrm{km})$ varied only slightly from those found by others (Boje, 1944; Margaria, Cerretelli et al., 1963; Howley and Glover, 1974). The low relationship between speed and caloric cost per unit distance $(r=-.019)$ indicated the energy cost of running a given distance is independent of the speed at which it is run (Margaria, Cerretelli et al., 1963). There is, however, a linear increase in energy expenditure per unit body weight and time $(\mathrm{Kcal} / \mathrm{kg} / \mathrm{min})$ over the entire running range (Figure 2). The regression equation for the 86 observations in this study was: Energy $(\mathrm{Kcal} / \mathrm{kg} / \mathrm{min})$ $=0.001$ Speed $(\mathrm{m} / \mathrm{min})-0.01(r=.920 \mathrm{SEE}=0.017$ $\mathrm{Kcal} / \mathrm{kg} / \mathrm{min}$ ). This agreed very closely with the equation produced by Costill and Fox (1969).

If the slopes of the regression lines of oxygen consumption on running speed were used as measures of efficiency (Foster, 1972), there was considerable difference in the economy of running in these runners. A $36.8 \%$ difference was observed between the most efficient and the least efficient runners. If the oxygen consumption at $268 \mathrm{~m} / \mathrm{min}$ was determined using each individual's prediction equation (Table II), the efficiency difference was $22.5 \%$, which is still well above the accepted advantage thought to be derived from training (Margaria, Cerretelli et al., 1963; Mayhew and Andrew, 1975). The efficiency difference in the present study was also greater than the $13.2 \%$ found for a comparable sample (Costill, Thomason et al., 1973).

\section{DISCUSSION}

It may be concluded that the oxygen consumption -

$\begin{array}{ll}\text { Kcal/km } & \text { Kcal } / \mathbf{k g} / \mathbf{k m} \\ & \\ 80.5 \pm 3.9 & 1.04 \pm 0.05 \\ 63.2 \pm 2.1 & 0.99 \pm 0.03 \\ 63.8 \pm 1.5 & 1.06 \pm 0.02 \\ 66.3 \pm 3.7 & 0.88 \pm 0.05 \\ 72.8 \pm 4.2 & 0.92 \pm 0.05 \\ 64.2 \pm 2.1 & 0.93 \pm 0.03 \\ 61.7 \pm 3.8 & 0.86 \pm 0.05 \\ 57.3 \pm 0.7 & 1.03 \pm 0.01 \\ 55.1 \pm 1.8 & 1.02 \pm 0.03 \\ 65.0 \pm 7.7^{b} & 0.97 \pm 0.07^{b} \\ 2.6 & 0.02\end{array}$

$\mathrm{Kcal} / \mathbf{k g} / \mathbf{k m} / \mathrm{min}$

$0.209 \pm 0.055$

$0.226 \pm 0.050$

$0.215 \pm 0.044$

$0.202 \pm 0.048$

$0.184 \pm 0.033$

$0.187 \pm 0.032$

$0.174 \pm 0.037$

$0.211 \pm 0.050$

$0.222 \pm 0.040$

$0.203 \pm 0.018^{b}$

0.006

speed relationship is linear over the entire aerobic range. Considering the values in the literature (Table III), Gt would appear that the variations in oxygen consumption around the means at different speeds are approximainey

\section{TABLE III}

\section{Comparison of Oxygen Costs of Horizontal Running}

\begin{tabular}{|c|c|c|c|c|c|}
\hline $\begin{array}{l}\text { Running } \\
\text { Speod } \\
(\mathrm{m} / \mathrm{min})\end{array}$ & $\begin{array}{l}\text { Wyndham } \\
\text { et al. }\end{array}$ & $\begin{array}{l}\text { Costill, } \\
\text { Thomason, } \\
\text { Roberts }\end{array}$ & $\begin{array}{l}\text { Mayhew } \\
\text { et al. }\end{array}$ & $\begin{array}{l}\text { Cureton, } \\
\text { Boileau, } \\
\text { Riner }\end{array}$ & $\begin{array}{r}\text { Present } \\
\text { Stud申 } \\
\frac{3}{3} \\
\frac{7}{0}\end{array}$ \\
\hline 161 & $\begin{array}{r}37.2 \\
\pm 2.4\end{array}$ & $(25.0) *$ & $(24.4)$ & $(25.6)$ & $\begin{array}{l}30 . \bar{s} \\
\pm 2 . \frac{f}{g}\end{array}$ \\
\hline 188 & $\begin{array}{r}38.6 \\
\pm 2.0\end{array}$ & $(31.8)$ & $(30.5)$ & (32.7) & $\begin{array}{r}36 . \bar{\sigma} \\
\pm 3 . \bar{Z}\end{array}$ \\
\hline 215 & $\begin{array}{r}41.6 \\
\pm 2.7\end{array}$ & $\begin{array}{r}40.4 \\
\pm 1.9\end{array}$ & (36.7) & 38.7 & $\begin{array}{r}41.48 \\
\pm 3.4\end{array}$ \\
\hline 241 & $\begin{array}{r}44.6 \\
\pm 3.3\end{array}$ & $\begin{array}{r}45.6 \\
\pm 2.0\end{array}$ & $\begin{array}{r}42.2 \\
\pm 2.1\end{array}$ & (46.7) & $\begin{array}{r}46.6 \\
\pm 3 . \overline{8}\end{array}$ \\
\hline 268 & $\begin{array}{r}48.1 \\
\pm 4.1\end{array}$ & $\begin{array}{r}51.7 \\
\pm 1.9\end{array}$ & $\begin{array}{r}48.8 \\
\pm 2.3\end{array}$ & 54.9 & $\begin{array}{r}54 . \overline{\underline{\Phi}} \\
\pm 4 . \overline{\mathrm{R}}\end{array}$ \\
\hline 295 & $\begin{array}{r}50.1 \\
\pm 5.3\end{array}$ & $\begin{array}{r}59.3 \\
\pm 2.5\end{array}$ & $\begin{array}{r}55.7 \\
\pm 2.3\end{array}$ & $(60.9)$ & (57) \\
\hline 322 & (53.1) & $\begin{array}{r}69.0 \\
\pm 4.2\end{array}$ & $\begin{array}{r}61.8 \\
\pm 3.5\end{array}$ & 69.1 & \\
\hline 349 & (55.8) & (72.4) & $\begin{array}{r}66.6 \\
\pm 3.3\end{array}$ & (75.1) & 100 \\
\hline 376 & (58.5) & $(79.2)$ & $(73.6)$ & 81.1 & 17 \\
\hline
\end{tabular}

* Values in (1) are predicted from the regression equation veloped from data in the respective studies cited. 


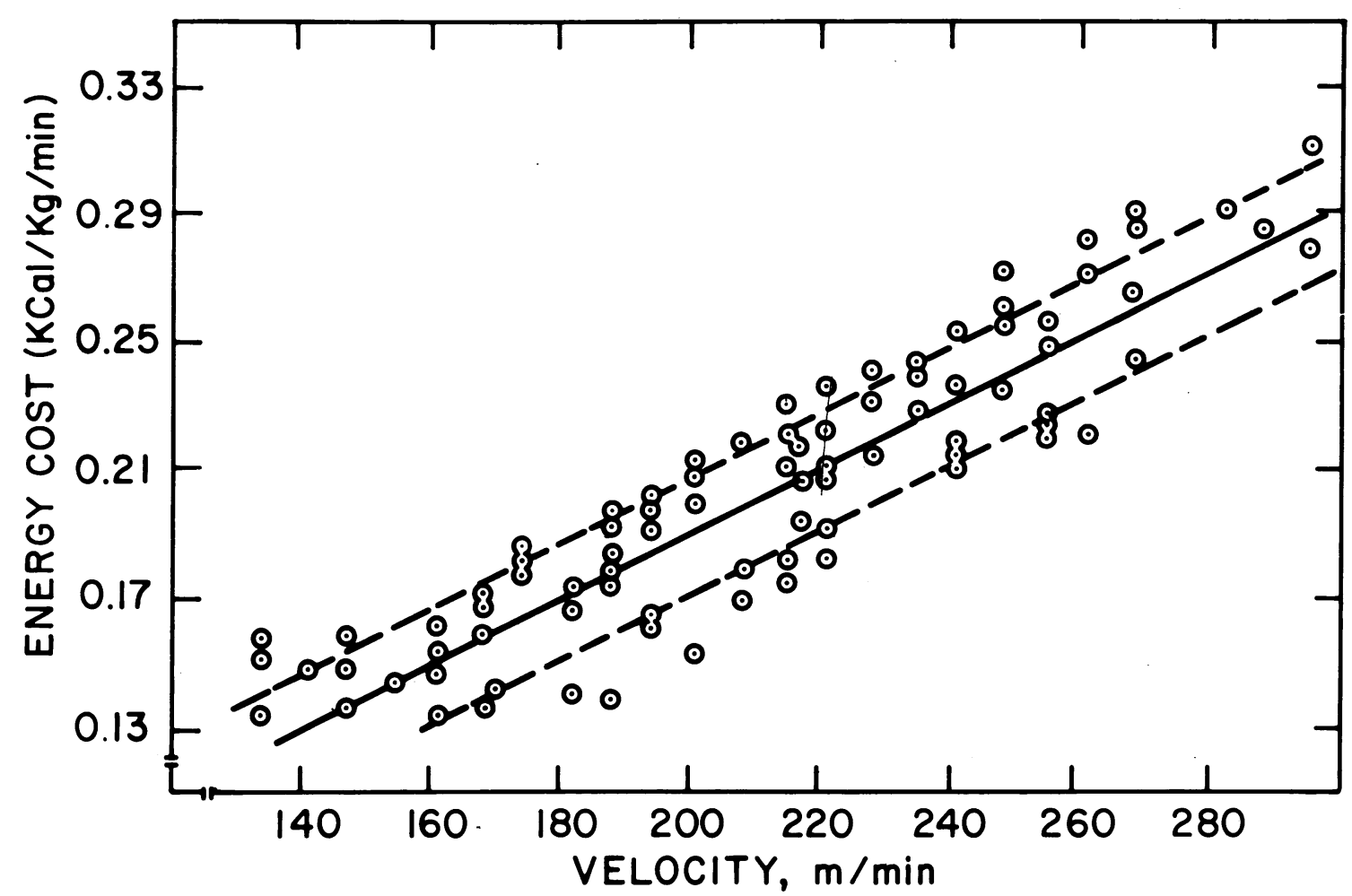

Figure 2. Relationship between running speed $(\mathrm{m} / \mathrm{min})$ and energy expenditure $(\mathrm{Kcal} / \mathrm{kg} / \mathrm{min})$ in 9 trained runners. $(\mathrm{Kcal} / \mathrm{kg} / \mathrm{min})=0.001$ Speed $(\mathrm{m} / \mathrm{minj}-0.01(r=.920$, SEE $=0.017 \mathrm{Kcal} / \mathrm{kg} / \mathrm{min})$.

equal within the individual studies. Between studies, however, there is considerable variation in the oxygen cost of running at similar submaximal speeds. Table III suggests that the variation is minimal at about 241 $\mathrm{m} / \mathrm{min}(\sim 10 \%)$ and maximal at either end of the continuum $(>30 \%)$. This may have been, in part, due to the sampling methods employed since extrapolation of $\mathrm{VO}_{2}$ values at higher and lower running speeds may not be accurate (Daniels, Krahenbuhl et al., 1976). As Daniels (1974a) has pointed out, these variations in efficiency may greatly affect the performance ability of endurance runners. Unfortunately, no common performance criterion was administered to the subjects in the present study.

If the slope of the individual runner's oxygen consumption - speed regression line is used as a measure of running efficiency, several interesting comparisons arise. $\mathrm{VO}_{2}$ max was significantly related to the slope of the regression line $(r=.700)$, which indicates that individuals with greater aerobic capacities tend to be less efficient runners. This fact is supported by observations on champion runners (Daniels, 1974b; Cureton, Boileau et al., 1975). Perhaps the greater maximal oxygen intake of superior runners allows them to be somewhat less efficient while running and yet maintain oxygen supply commensurate with demand at higher speeds.
Although the years of training for each runner was not significantly related to $\mathrm{VO}_{2} \max (r=-.041)$, it was significantly related to running efficiency as measured $\varrho$ by the regression slope $(r=-.621)$. Thus, while most of $\bar{O}$ these runners may have reached a stable $\mathrm{VO}_{2} \max$, the years of training appear to contribute to their improved efficiency. This may add support to the supposition of year-round and life-long training for endurance athletes.

The recent employment of the fractional utilization coefficient of the maximal aerobic capacity as a means?

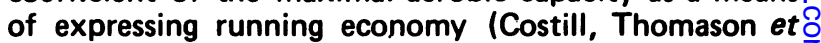
al., 1973) prompted a comparison with the slope of the regression line. The resulting correlation was low and을 insignificant $(r=-.033)$, suggesting the two factors might measure different components of efficiency. Indeed, it has been suggested that $\% \mathrm{VO}_{2}$ max represents not only the relative oxygen cost of submaximal run-o ning, but also the potential of an individual to extend $\tilde{O}$ himself to a maximal level (Costill, Thomason et al., $N$ 1973; Mayhew and Andrew, 1975). Further study of the regression slope as a measure of running efficiencyo appears warranted.

Finally, it is interesting to note that when oxygen $\frac{7}{0}$ consumption is expressed relative to body weight, there 
appears to be an optimal running speed for these subjects. Using the mean oxygen consumption values for each speed observed in the present study, two distinct regression lines appear evident (Figure 3 ). The intersection of the two regression lines occurs at approximately $185 \mathrm{~m} / \mathrm{min}$, or $11.1 \mathrm{~km} / \mathrm{hr}$. Sellers (1973) found his untrained subjects to show optimal oxygen consumption at $11.0 \mathrm{~km} / \mathrm{hr}$. While this speed is far below any training or racing speed employed by the present subjects, it suggests that in running, as in walking
(Ralston, 1958), there is an optimal movement speed.

In conclusion, while there is a linear relationsh between oxygen consumption and running speed, there is considerable variability in the submaximal oxygen cost of trained runners. The degree to which such variability affects running performance is worthy of further invest.gation. Also, the fact that individuals with higher aerobsc capacities exhibit lower efficiencies further supports the need for a high $\mathrm{VO}_{2}$ max in distance running.

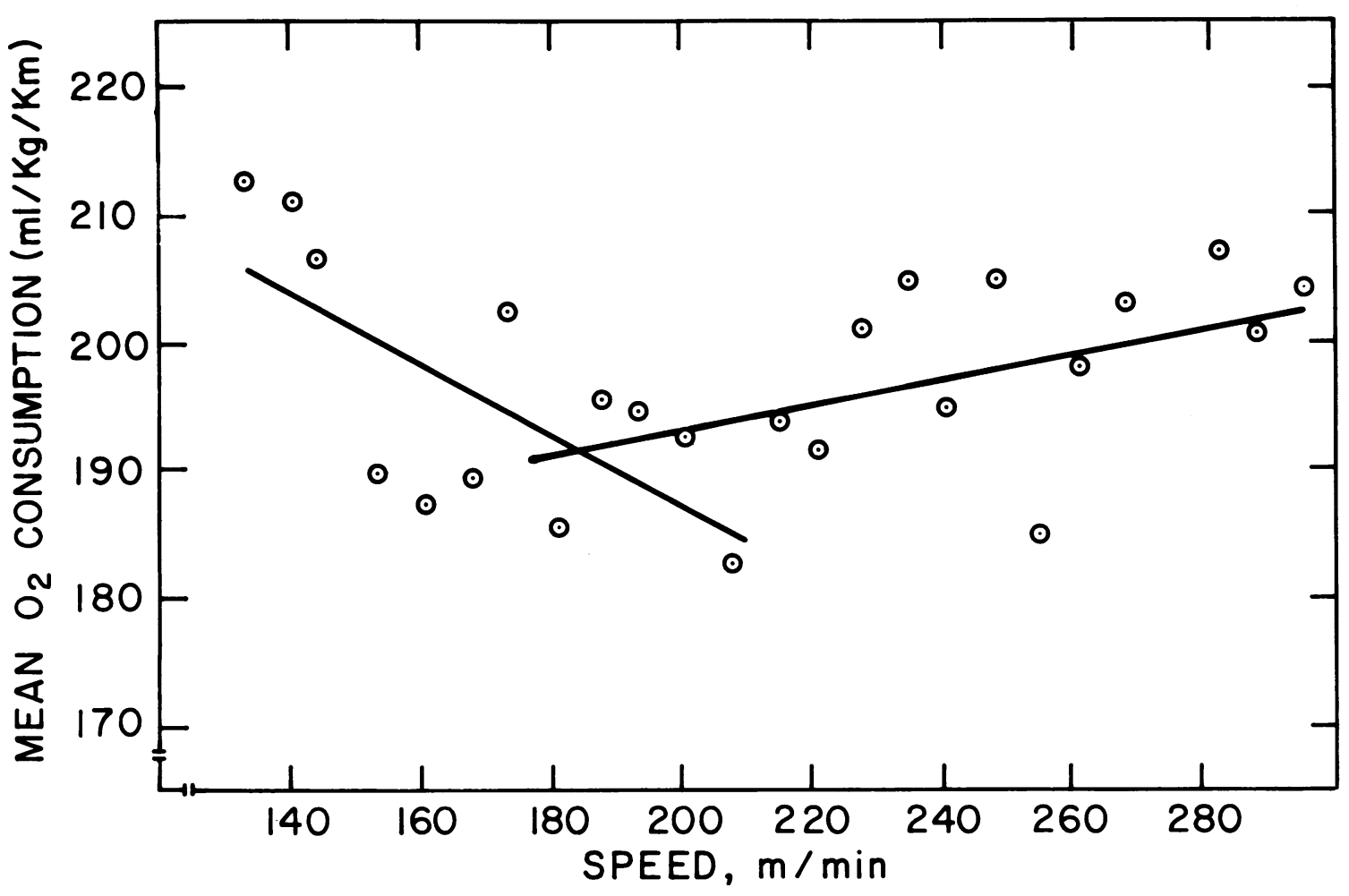

Figure 3. Relationship between running speed and mean oxygen consumption in 9 trained runners.

\section{REFERENCES}

Boje, O. 1944. "Energy production, pulmonary ventilation, and length of steps in well-trained runners working of treadmill", Acta Physiol.Scand. 7, 362-375.

Costill, D. L., and Fox, E. L. 1969. "Energetics of marathon running", Med.Sci.Sports 1, 81-86.

Costill, D. L., Thomason, H., and Roberts, E. 1973. "Fractional utilization of the aerobic capacity during distanfo running", Med.Sci.Sports 5, 248-252.

Cureton, K. J., Boileau, R. A., Wieneke, G. R., and Riner, W. F. 1975. “Structural and physiological evaluation of Crâg Virgin, 1975 NCAA cross country champion". Unpublished research, Physical Fitness Laboratory, University $\underset{\oplus}{\Phi}$ Illinois, Champaign, III.

Daniels, J. 1974a. “Physiological characteristics of champion male athletes”, Res.Quart. 45, 342-348. 
Daniels, J. 1974b. "Running with Jim Ryun: a five-year study", Physician and Sportsmed. 2, 63-67.

Daniels, J., Krahenbuhl, G., Foster, C., Gilbert, J., and Daniels, S. 1976. “Aerobic and cardiovascular responses of female distance runners to submaximal and maximal exercise", Paper present at the Conference on the Marathon: Physiological, medical epidemological and psychological studies, New York, N.Y.

Dill, D. B. 1965. "Oxygen used in horizontal and grade walking and running on the treadmill", J.Appl.Physiol. 20 19-22.

Dill, D. B., Talbott, J. H., and Edwards, H. T. 1930. "Studies in muscular activity", J.Physiol.(London), 69, 267-305.

Foster, C. C. 1972. "Maximal aerobic power and the aerobic requirements of running in trained runners and trained non-runners". M. Ed. thesis, University of Texas, Austin, TX.

Howley, E. T., and Glover, M. E. 1974. "The caloric costs of running and walking one mile for men and women", Med.Sci.Sports 6, 235-237.

Margaria, R., Cerretelli, P., Aghemo, P., and Sassi, G. 1963. “Energy cost of running”, J.Appl.Physiol. 18, 367-370.

Mayhew, J. L., and Andrew, J. 1975. "Assessment of running performance in college males from aerobic capacity percentage utilization coefficients", J.Sports Med.Phys. Fitness 15, 342-346.

Pugh, L. G. C. E. 1970. "Oxygen intake in track and treadmill running with observations on the effect of wind resistance", J.Physiol.(London) 207, 823-835.

Ralston, H. J. 1958. "Energy-speed relation and optimal speed during level walking", Int.Z.angew Physiol. 17, $277-283$.

Sellers, W. R. 1973. "The energy cost of zero grade running related to exercise prescription for body weight control' Ed. D. thesis, Boston University, Boston, MA.

Wyndham, C. H., Strydom, N. B., van Graan, C. H., Rensburg, A. J., Rogers, G. G., Greyson, J. S., and van der Walt, W. H. 1971. "The energy cost of walking and running at different speeds", So. African Med.J. 45, 50-53. 